\title{
DONDE LAS MUJERES PAREN MONTADORES...
}

\author{
Henry Sevilla Morales*
}

- Eh, Frijolón, que no te vaya a botar el toro. Arriba, carajo, no le llevés miedo: Vos sos el gallo.

- Eso es, pariente, bien agarrado ese pretal, no le aflojés al Venado. ¡Bien pegado al cuero, bien pegada esa espuela!

- No te le agüevés, mi Frijol, que el hombre es más hombre cuando está sobre los lomos del diablo...

Frijolón tiene las manos bien metidas ya entre el pretal y el lomo del toro; las espuelas, bien amarradas a las botas chontaleñas; los muslos, aferrados a los costados del animal, que resopla y espumajea furia por las fauces. Va a montar rústico, como montan los verdaderos hombres de La Bajura: Sin verijeras y sin casco, sin gallos ni nada de eso que los guanacastecos llaman "mariconadas de cartagos", pues la victoria del montador sobre el toro debe ser fruto solo de su coraje y de su hombría... Frijolón ha bajado ya varios sorbos del aguardiente que lleva en el cacho fajado al cinto. Se acomoda sobre el toro. Tiende la mirada hacia el tumulto de gente y mira entre la muchedumbre a Cástulo Rocha, que ha venido a ver la monta y que (cree) lo mira con una risa burlona que lo hace sentir ineluctablemente humillado. El toro da un colazo que cae sobre la espalda de Frijolón, dibujándole una mancha de orines revuelta con estiércol que lo saca de sus meditaciones. Pero, como todas las veces que toma, se le ha empezado a atragantar el recuerdo perdido de la Martina, que se le ha ido con otro, o, más bien, el recuerdo del otro, que le ha quitado a su Martina. No está seguro de su nombre, pero la risa burlona de Rocha le hace pensar que pudo haber sido perfectamente él ( $\succsim_{\mathrm{O}}$ tal vez Evelio Traña o Santos Narváez?) quien le quitó a aquella potra de piel a fuego ardiendo por la que tantas veces había tenido que probar su honor a punta de puño y cruceta. Frijolón siente un borbotón de rencor espolearle el coraje: "Debo matar a ese pendejo de Cástulo Rocha, debo matarlo" se repite (cree estar seguro ahora de que es él con quien se le ha ido la Martina), olvidando por completo que su ahora mujer, Agustina Morales, se ha quedado llorando en casa, temblando de miedo de saber que él llegará borracho por la madrugada, gritando "Agustina, quiero caldo de gallina, quiero beber sangre", y repitiéndole que es a la Martina y no a ella a quien quiere, y que ella es sólo el clavo que ha llevado a casa para sacarse el clavo de furia que desde hace meses lleva metido en el pecho.

Frijolón toma con fuerza el pretal y mira de nuevo al toro, que resopla a intervalos entrecortados, golpeando los postes y las

Universidad de Costa Rica. Profesor. Costa Rica. Correo electrónico: al_deron@hotmail.com Recepción: 25/10/2014 . Aceptación: 30/4/2015. 
reglillas, mientras los otros montadores lo envalentonan desde el otro lado del corral, y Frijolón piensa que, por ahora, el honor del que debe ocuparse es el de parar a aquella bestia descomunal llamada el Venado. Frijolón siente la sangre acelerársele, y palpa con las piernas la máquina de muerte que tiene que parar: Se impacienta. El toro infla los pulmones. Frijolón siente sus nudillos batirse contra la presión que la respiración del toro ejerce sobre el pretal (¿Y el poco-hombre de Rocha, estará mirándome todavía?). El montador mira el lomo membrudo, la nuca manchada a trechos y la testa amplia que arremete a cornadas contra las reglillas de la manga, y cae en la cuenta de que el Venado es el toro más grande y peligroso que en la vida se haya atrevido a montar. La adrenalina se le trepa ahora al pecho. El calor le hace sudar los muslos, y por el vientre de la bestia siente bajar gruesos hilos de sudor caliente; la sangre, el lomo, los costados, todo el toro es un hervor de músculos a punto de reventar en saltos.

Allá en lo alto, sobre el cielo ominoso que se curva sobre Santa Cecilia, una espiral de zopilotes vuela con la parsimonia casual de ese pueblo donde, como en San Luis de los Jaúles, la maldad y la muerte galopan cuales reinas tenebrosas por las callejuelas y las almas de la gente. Frijolón siente el corazón de la bestia agitarse en un bombear potente, y se aferra a la espuela corrediza, a sus manos macizas y a la buena suerte que desde siempre le ha traído en la monta el garrobo muerto que carga en la bolsa izquierda de su pantalón. Está solo sobre los lomos del diablo, que ahora se le parece el doble en tamaño; está solo, con sus botas de cuero y su hebilla ancha; solo, frente a un espectáculo que le puede costar la vida o, peor para su suerte, la humillación de no haber parado al Venado sabiendo que desde las gradas puede estarlo mirando Cástulo Rocha. Frijolón palpa el garrobo muerto en su bolsillo y masculla: Oh, garrobo de los llanos, yo te conjuro... Oh, garrobo de los montadores, yo te invoco... Dame tus uñas y tu fuerza, oh, gran garrobo invencible... Frijolón asegura de nuevo el pretal entre sus manos, y sigue mascullando: ...Haz que el golpe yo resista y a mis enemigos venza, y haz que en esta monta, como en el llano solitario, pare yo a este toro y esquive el acero filudo de la cruceta... Frijolón respira hondo, y, terminada la oración, el corazón se le llena de algo que se le está pareciendo mucho al miedo. Todo es un suspiro largo y tortuoso antes de que, finalmente, Frijolón tiene al toro bien acomodado y en dirección hacia la plaza, y grita: ¿PUERTAAAAA!

El toro da un tirón, salta sobre sus setecientos kilos dando cornadas, se corva, resopla, cae, da un giro, tuerce la testa buscando el pecho del montador, llena los pulmones de aire, salta nuevamente, dando más cornadas, exhala a bocanadas, resopla enfurecido, tira por su hocico espuma, vuelve a cargar los pulmones, salta nuevamente, busca con los cuernos y la testa, se tuerce, cae sobre las patas delanteras, vuelve a hinchar los pulmones y vuelve a saltar, iracundo. El montador se aferra con las espuelas, sujeta el pretal, que le estruja los nudillos, se mueve con cadencia y gran garbo al ritmo de los tirones de la bestia, se tuerce, se columpia, respira sofocado... siete segundos que le parecen siete horas, escapa a una cornada, se aferra a la vida, los músculos se le contraen, las piernas ceden... nueve segundos, el alcohol le golpea el cerebro, se marea, se desvencija sobre los lomos de la bestia... once segundos.... De repente, casi vencido, lleno de una flacidez creciente, siente el toro saltar con fuerza inusitada, suelta una mano, se tuerce sobre los lomos de la bestia, se va a caer, se está cayendo... El toro viene en descenso, exhalando aire caliente revuelto con babas de furia, cae sobre sus patas delanteras, cae con mayor peso sobre la izquierda $\mathrm{y}$, de súbito, se le desploman los setecientos kilos sobre la pata, el montador toca apenas el suelo y se reincorpora, absorto, pero victorioso... El toro ya ha lanzado un bramido corto y hosco, se mira su pierna desencajada moverse al compás desorbitado del cuerpo, y otro bramido de tormento invade la plaza y el corazón supersticioso de los espectadores que se santiguan, aterrados de ver otro toro que habrá de morir quebrado tras la monta de Frijolón, que ya ha adquirido fama de quebrador de toros y que acaba de llevar al Venado al término de su existencia. 
Esa tarde, entre cuchicheos agoreros y garrafas de aguardiente, Santa Cecilia comió carne en abundancia y a precio muy bajo, pues hubo que sacrificar al toro y vender la carne en los cuatro chinamos donde había ya gran abundancia de carne chisporroteando en las cazuelas enormes y ahumadas por el hollín de la leña. La fama siniestra de Frijolón se hizo más evidente y el Venado pasó a ser el acompañamiento extra de las tortillas palmeadas y del aguardiente que de sobra se sabía se tomarían todos en la borrachera que eran siempre las montas de Santa Cecilia. La monta continuó hasta entrada la noche sin mayor novedad. Montadores y espectadores comieron y bebieron como de costumbre, y mujeres y niños rogaron a algún Santo para que los montadores no acometieran alguna de las barbaridades que ya formaban parte del cotidiano de Santa Cecilia. Esa noche, también, contrario a todo pronóstico, Frijolón no armó ninguna riña, ni volvió a pensar en la Martina, ni en el rencor encarnizado que sentía contra Cástulo Rocha, sino que bebió solitario y hasta el cansancio en los alrededores de la plaza, entre llantos silenciosos y un semblante hosco (casi sombrío) que llamó la atención de la muchedumbre que, aunque horrorizada por el episodio ominoso de la monta, extrañaba el rito de entretenimiento que eran las peleas bajo el viejo decir de que monta donde no hay sangre no es buena monta.

$* * * * *$

Además de ser una leyenda en la tradición de monta en el pueblo de Santa Cecilia, Celedonio Isidoro de San Francisco Morales Argueta era también un fantasma casi sin nombre que causaba en la gente una ristra de emociones contrapuestas que oscilaban entre la lástima y el miedo, entre el desprecio y la compasión; no sólo por ser un montador de gran fama y a la vez un llorón hasta el cansancio, principalmente cuando se embriagaba, sino por la paradoja misma de tener un nombre y un cuerpo tan largos, y un apodo tan breve, tan resonante y tan busca pleitos (como solía decir su madre con cierto aire de juramento cuando lo veía llegar ensangrentado después de cada monta), que no era difícil comprender por qué la gente prefería llamarlo por el sobrenombre de Frijolón y no por su nombre real.

Así era. Frijolón era una extraña figura sin nombre ni apellidos, cuyo caminar siempre acompasado por el chasquido metálico de las espuelas corredizas, y engarbado por las botas de cuero chontaleño bien curtido, las polainas de cuero crudo y el cuerno barnizado colgado al cinto, anunciaban el espectáculo certero de la buena monta, de la algarabía de la gente y del furor de las peleas entre montadores (pues, era menester demostrar que no sólo se era buen montador, sino también un buen peleador, con los puños y también con la cruceta) que empezaban siempre por una riña mano a mano entre los oponentes, y que terminaban por lo general con varios hombres macheteados que se sumaban pronto al zafarrancho; con el llanto de los hijos de los peleadores, y con la obra devota de las madres que les paraban la hemorragia poniendo puñados de sal en la herida viva, ya que sus mujeres habían adquirido con los años la indiferencia habitual de casi todas las mujeres de montadores borrachos de Santa Cecilia, y que hubieran deseado dejarlos morir de alguna resaca si no fuese porque todas carecían del valor para tan necesario reclamo de la dignidad humana.

Pero aquel sábado 25 de julio de $199 . .$. fecha en que los guanacastecos celebran la Anexión del Partido de Nicoya a Costa Rica, y día también que sucedió a aquella monta tan recordada (no sólo por la muerte del Venado, sino por haber sido la única vez en que Frijolón no armó pleito), el corazón de Santa Cecilia se habría de vestir de azul, blanco, rojo y verde; pero principalmente de rojo, pues un montador estaba a punto de decir adiós al lema de casi todos los montadores guanacastecos de que soy de una tierra de hombres bien arrechos, donde los ríos son de leche y las piedras son cuajadas, y donde las mujeres paren montadores, ¡no cualquier cochinada!

Como todos los días después de las montas, Santa Cecilia había amanecido enferma. Tenía el aire un calor espeso y apremiante, que se conjugaba con la monotonía de los pobladores, y 
con la impresión de tristísimo silencio que dejan al día siguiente las montas de pueblo. Las casas, viejas y destartaladas, con sus corredores ocres de tres por tres, sus techos de doble caída de agua, el blanco-amarillento que se encostra en las paredes luego de años de descuido y polvo, las mujeres gordas, lentas y perezosas, los niños renegridos y tristes, las callejuelas agrietadas, y los montadores tendidos, casi borrachos todavía, con la boca pastosa y fétida, eran los escombros ineluctables que años de tradición habían producido no solo en el paisaje, sino también en los corazones de aquella gente.

Eran las seis menos quince de la mañana y el sol había salido ya, como un disco sangriento, tras la carpa verde-reseca de la loma que resguardaba la choza de Frijolón. Agustina Morales dormía (o se fingía dormida), horrorizada por la certidumbre de que Frijolón había amanecido otra vez borracho (lo supo por los narco-corridos que sonaban ya en la radio) y que, como era costumbre, rugiría pronto, reclamando la sangre de su brazo. "Rara cosa que no lo hiciera cuando llegó en la madrugada, y también que no me haya despertado para que le matara una gallina", pensó Agustina.

$Y$ es que era una costumbre de años que aterrorizaba a Agustina cada vez que Frijolón regresaba de una monta. Desde el día en que él la "liberó" de la violencia que su padre le había perpetrado desde niña cada que se emborrachaba, ella llegó a la conclusión de que la única violencia mayor a la de las bestias salvajes era la violencia del ser humano, y que entre todas las violencias humanas, la más implacable era la que se enraizaba entre los familiares, pero más aún entre los familiares que decidían volverse hombre y mujer, bajo el sello maldito del incesto.

Así la había maldecido el destino. A punto de matarse por el horror de la ira de su padre y de los abusos de los primos que dormían hacinados en una pieza común, Agustina Morales accedió sin mayor preámbulo cuando, a sus escasos catorce años, Frijolón le propuso escaparse de madrugada con él y convertirse esa misma noche en mujer de un solo hombre, y, mejor para su suerte, no cualquier hombre. Como una premonición de su desgracia, la misma noche que se escaparon, sintiendo el aliento rancio de su raptor mientras corrían asediados por las nubes de sancudos entre los chaparrales espinosos de la finca, Agustina supo que algo mucho peor le esperaba con aquel primo casi desconocido que ella prefería pensar como uno muy lejano. Pero a pesar de la resistencia que había desarrollado contra la agresión, Agustina nunca pudo acostumbrarse a ese hábito aberrante que tenía Frijolón de chuparle la sangre del brazo cada que llegaba borracho de las montas. Por eso se sintió fulminada por la voz pedregosa de Frijolón que rugió de pronto, a las seis y quince de la mañana de aquel sábado aciago: Agustina, tengo ganas de beber sangre-

Sin darle tiempo de reponerse del sobresalto que le provocó el terrible llamado, Frijolón tomó a Agustina de la mano, y la arrastró hecha un temblor hasta la loma junto al cocotero donde siempre le gustaba sangrarla. Allí le descubrió el brazo moreno, allí vio sus ojos pardos suplicar en un silencio servil y prolongado, y allí hundió el machete carnicero, haciendo brotar la sangre negro-rojiza que luego sorbió con maniática perversidad, mirando el rostro quebrantado de Agustina, que sollozaba como hacia adentro, muerta de miedo y de unas ganas ubérrimas de matarse.

Acabado el ritual post-ingesta (pues lo hacía, según decía, para ayudarse a sacar la goma), Frijolón le dio una palmada desdeñosa en la espalda, como diciendo: - Ya lo vez, fue más el susto, andá ahora a prepararme un caldo de gallina-. Acto seguido, Frijolón rasgó su camisa de Docoma raída y le vendó el brazo, deteniendo el sangrado y diciéndole que tenía que acostumbrarse a esas cosas, que la que se casa, casa quiere, y que en aquella casa, se hacía lo que a Frijolón se le antojase.

Agustina se escurrió tras la cortina vieja que hacía de puerta del cuarto, dejando a Frijolón terminar de sacarse la goma con lo que le quedaba en el cacho barnizado que usaba de garrafa para llevar el aguardiente. Hecha un ovillo sobre la cama, Agustina maldecía la hora en que las entrañas de su madre la escupieron sobre la escena macabra del mundo, y la hora mezquina 
que la dejó huérfana de madre a tan solo minutos de haber nacido. Por eso no cesaba de repetirse que las infidelidades que desde siempre le había profesado a Frijolón estaban justificadas, a pesar de que su conciencia no dejaba de perseguirla con los moralismos más inexplicables, pues, por más que lo intentaba, Agustina no lograba recordar eventos que no involucraran las más perversas inmoralidades acometidas contra su cuerpo y su espíritu, y los de todas las mujeres que, al igual que ella, arrastraban un pasado cargado de abusos, de mansedumbre y de dolor irremediables. Por eso, mientras yacía postrada en su cama, escuchando a Frijolón sorber el aguardiente de su cacho barnizado, se entregó a sus anchas al pensamiento de que era una tremenda ironía que los montadores de aquel pueblo de pendejos llevaran esos cuernos fajados en el cinto, y no erguidos sobre la frente, como bien merecido lo tenían.

$\mathrm{Y}$ así, mientras Agustina se atragantaba de rencores sobre la cama, Frijolón sollozaba, hermético, postrado sobre la mesa de tres patas y bebiendo más del aguardiente de la hombría, pero recordando el horror que también él había vivido de niño, cuando un tío que se había mudado a vivir en su casa lo sangraba en los potreros cada que amanecía con resaca, y lo obligaba a decir que la herida había sido un accidente de machetero novato, caso típico en los niños que se inician en los oficios del campo. De este modo, Frijolón cayó en la cuenta de que las maldiciones son heredadas en forma de hábitos, y que pasan de generación en generación, como había escuchado en algún momento repetir en la misa de domingo, y pensó que es por eso que los hijos heredan de sus padres desde la forma de rascarse la espalda (como en su caso, que se rascaba la espalda con el filo del machete, al igual que lo hacía su padre), hasta los impulsos de violencia más comunes, como el hábito de agredir a la mujer o de matar cuanto animal tuviera movimiento y que no fuera cazado durante los días sagrados de la Semana Santa. Así que Frijolón siguió tomando, y tomó hasta emborracharse nuevamente, cayendo en un letargo que aumentaba mientras el sol subía y subía con él también el sopor del día.
Cuando, al cabo de unas horas, lo despertaron las teclas de las marimbas que El Negro Bluefileño y Odilón Carrillo hacían crujir al ritmo de El Torito y El Punto Guanacasteco, Frijolón notó que Agustina había huido de casa con los pocos enseres que había hecho caber en un hatillo - hatillo que desde hacía tiempo tenía preparado para la huida, pero que nunca se había atrevido a llenar por miedo de que la vida fuera tan perra como para no dejarla que se muriera de hambre en la montaña donde siempre había querido morirse- - Cuando Frijolón entró al cuarto, sólo halló la venda con que había detenido el sangrado sobre la cama, y pensó que poco le importaba aquella huida. "Vieja mal agradecida, como si estuviera mal comida o mal cogida la gran chancha esa...", se dijo a sí mismo Frijolón, sin terminar de creer que de verdad ella se le había ido. "A la mierda con la Agustina: En mejores pailas he frito mis huevos", gritó, y se echó tres tragos de aguardiente a pico de botella y sin respirar. Las marimbas crujían afuera, acompañadas de bombas y retahílas, creando un ruido que llegaba como desde muy lejos a la consciencia arracimada de Frijolón, que ya se encontraba embrocado sobre la mesa de tres patas con la boca entreabierta y chorreando alcohol y babas.

El bullicio de las marimbas lo mantuvo medio despierto por largo rato, hasta que, sin más tregua, se le fue clavando la imagen de la Martina cada vez con más fuerza en el corazón, así que el mareo fue desapareciendo como por arte de un horrible ensalmo de muerte. Frijolón se golpeó la cara con las manos y se puso de pie, desorbitado pero casi lúcido, y los ojos se le llenaron de mal, y las ideas le empezaron a revolotear, como mariposas venenosas, en el oscuro abismo de su alma: "¡Voy a matarlo!", se dijo. "Sí señor, voy a matar a esa chanchada de hombre". Y en tanto que se había decidido a matar a Cástulo Rocha, trató de darse más valor acariciando con los ojos sus tesoros de monta: $\mathrm{Su}$ montura de cuero crudo sobre la cercha, sus botas de cuero, sus espuelas corredizas y el sombrero alón que lucía con donaire después de las montas, sus tres tajonas de verga de toro colgando de los horcones, cerca de la cercha, su 
vaqueta de cuero blanco, el jícaro con garrobos muertos para la buena fortuna en la monta y contra los enemigos, las cabezas molidas de culebra para prevenir la debilidad de la carne de su mujer ("pedazo de baboso", pensó, "como si no se me hubieran ido ya las dos") y el trapo embebido de orines que colgaba por las noches en los horcones para que los coyotes no llegaran a comerse las gallinas...

¡Sí que lo va a matar! Porque hacía mucho que debía haberlo matado. "A Frijolón nadie le quita la mujer" /Echame ese toro pinto/. "¡No señor! No al mejor montador de Santa Cecilia," /hijo de la vaca mora/ "gran hacendado y dueño de cienes de cabezas de ganado" (fantasea) /para sacarle una suerte/... Esas ancas de potra salvaje sólo las puede cabalgar él. Y es que no es para menos (medita) /que te coge el toro, Simona/, la Martina es un mujerón, y la verdad es que ningún pendejo como Cástulo Rocha está a la altura de tener a una mujer de esa talla /que te coge el toro, Marcela/... Y luego: /Mi espíritu nunca muere/ / porque ha nacido junto al corral/... y después: / mi empeño son los caballos/, /las vacas todas/ /y mi mujer/... “¡Y mi mujer!” rugió Frijolón, ”y mi mujer... ¿dónde está mi mujer?”/el rancho, los chacalines, y esta pampa que no olvidaré/...

Frijolón tragó dos sorbos más, pero en vez de emborracharse, más bien terminó por olvidarse que estaba borracho, y partió así, cruceta en mano, hacia su venganza. Llevaba la sangre hirviendo, como hervía el sol que, a escasas diez de la mañana, tenía a Santa Cecilia revuelta en sudor, polvo y borrachera.

Pasó frente a la cantina "El Pescadito", lugar donde estaban instalados los marimberos y donde se vendían vigorones y chicharrones de cerdo que los cecilieños comían con gran voracidad, con esa extraña capacidad que tienen algunos guanacastecos de comer cerdo sin bebida; sólo con la saliva de sus gargantas.

- Eh, Frijolón, estas no son horas de armar bochinche. ¿Qué vas a hacer con esa cruceta desenvainada que llevás ahí? - Le gritó una voz que no pudo reconocer entre la multitud y la música de las marimbas.
- Que le voy sacar las tripas a Cástulo Rocha. Atájenme que llevo el diablo adentro-, respondió Frijolón.

— Dejate de guaruras y andá a dormir-, le respondió alguien entre el gentío. - Estás borracho y no podés ni con tus propias carnes-

- Vení para rebanarte las orejas a vos también, dejate ver, chanchada de hombre-, respondió Frijolón, mientras escuchaba la gritería que ya no era por la música ni por la algarabía de la Anexión, sino por el ridículo que estaba haciendo al gritar que iba a matar a Rocha en el estado en que se encontraba, y también por el bamboleo de su cuerpo cada vez que estrellaba la cruceta contra el lastre para intentar sacarle chispas a las piedras y demostrar a la gente que, borracho o sobrio, igual tenía dos huevos enormes colgando de entre las piernas que probaban que era no solamente fino montador, sino también gallo entre los gallos y hombre entre los hombres.

Gritos iban y gritos venían, dime que te diré, bulla, aguardiente y marimba, Frijolón tambaleándose a pasos torpes, la cruceta dando de plano contra las piedras, las chispas y el chasquido del metal contra la carretera: un completo bullicio; pero, por alguna razón inverosímil, no se armó pleito, las burlas fueron cesando y Frijolón terminó por esquivar la multitud entre gritos sabaneros y el tambaleo de su cuerpo que avanzaba desorbitado. Siguió a paso lento por la callejuela reverberante, pasando frente a la cantina clandestina del chino Alex; y después a un costado de la plaza donde el día anterior había batido su suerte contra el Venado: Un paisaje desolador, todo atestado de latas de cerveza y colillas de cigarro, de hojas de tamales y de perros lamiendo la grasa tirada de los chinamos... niños macilentos buscando monedas entre las latas, caparazones de armadillos que ("seguramente", pensó Frijolón) habían hecho pasar por chicharrones de cerdo las cocineras de los chinamos... vísceras de garrobo, la manga de la plaza, el recuerdo del Venado y de la Martina... Frijolón se enardeció de nuevo. Dejó atrás la plaza y se desvió por un callejón que lo llevaría hasta el rancho de Cástulo Rocha, pasando por el Río Sucio, donde cruzó con gran 
dificultad la viga de Cedro amargo que hacía las veces de puente sobre el caudal pedregoso, acentuando su creencia de que el guaro aleja el peligro del hombre. Vio los potreros secos de Cástulo Rocha, los cañales de Bambú con las hojas deshilachadas y las vacas flacas rumiando a la sombra de un Cenízaro.

Frijolón tuvo la sensación de que perseguía una causa absurda, y se enfureció consigo mismo, y se repitió una y otra vez el motivo que tenía para matar a Rocha, y se encontró rumiando memorias que nunca antes había escudriñado. Cosas sin sentido. Agustina curándole una herida en la frente, su padre muerto en un féretro de Caoba, sus días de agonía por la mordedura de la Terciopelo, rodeado de velas y mujeres rezando toda clase de ensalmos e invocando a curanderos muertos cuyos nombres no alcanzaba recordar, la sed desgarradora de las resacas en las madrugadas, tumbado sobre la mesa de tres patas desde donde llamaba a Agustina para sangrarle el brazo, las veces y formas en que había deseado a la Martina de adolescente, cuando la miraba jugar a las escondidas con sus amigas y veía dibujársele, como dos duras almendras, las puntas erguidas de los pechos que desde entonces llevaba empotrados en la memoria. Pero en ninguna de estas memorias se le apareció el momento en que la Martina se le fue de la casa, y concluyó que el guaro, además de protegerlo de los peligros, tenía también la propiedad borradora de eventos humillantes que siempre quiso mantener vivos a fin de encontrar el momento oportuno para cobrar venganza y limpiar la honra manchada que tanto estorbo le causaba.

Obnubilado en sus reflexiones, y buscando con la mirada a Rocha en el rancho que ya se divisaba cercano, Frijolón tropezó contra una piedra, perdió el equilibrio y se vino hacia adelante. La cruceta se clavó en el suelo evitándole una caída, pero las piernas le temblaban y la espalda se le bañó en sudor, producto de la resaca, de la borrachera revivida y del sol inmisericorde que se ceñía sobre el día. Avanzó a paso lento y decidido, y llegó finalmente al rancho del contrincante. Desde la entrada, Frijolón pudo ver a Cástulo Rocha que molía maíz en la vieja máquina de acero. A un lado de la máquina, una pequeña echaba tazones de maíz reventado en la copa. El pecho ancho, la espalda vigorosa y los brazos dilatados de Rocha estaban llenos de sudor.

- He venido a matarte-, rugió Frijolón, sosteniendo la cruceta en su mano izquierda. Mandá a la niña para adentro.

- ¿Qué le pasa, amigo? Yo a usted no lo conozco. Lárguese ahora mismo-, bramó el otro.

- ¡Que mandés a la mocosa para adentro, pendejo! - Y avanzó tres pasos, sigiloso, sobre la hierba.

Cástulo Rocha soltó el mango de la máquina y se colocó delante de la niña: — No te movás, hija —, le ordenó.

La niña se arrinconó entre la leña, detrás de la máquina, y Cástulo Rocha dio un salto para caer frente al cuerpo furibundo del otro. Como no tenía machete ni cruceta cerca, tomó un palo de escoba de monte entre las manos, y se lanzó al encuentro del enemigo. Rocha se mantuvo en guardia por unos segundos, mirando al otro temblar de ira, rígido de rostro y extraviado de espíritu, hasta que, de súbito, se encontró esquivando un machetazo que, de no haber saltado hacia atrás con la agilidad que saltó, le hubiera propinado una herida sin tregua en el abdomen.

Dos, tres, cuatro... Llovieron los machetazos. Rocha los esquivaba con diestra ligereza: Unos, apartando raudamente el cuerpo; otros, frenando el golpe con el palo de la escoba. La cruceta, liviana y afilada, cortaba el viento quieto de la mañana, entre silbidos y tajos desorientados que hacían de aquel ataque un acto desesperado que Rocha pudo percibir con suma frialdad. La niña, hecha un ovillo entre la leña, gritaba con desesperación: "Señor malo, no mate a mi papá, mi papá no le ha hecho nada..." Frijolón seguía buscando al otro con la cruceta, rebanando el aire, trastabillando, equivocándose. El otro, al ver el palo ya cortado y achicado por los machetazos, gritó a su hija por ayuda: 
- Pasame la rula, hija-, y volvió a esquivar otro machetazo. La niña pareció no escuchar, siguieron cayendo los ataques de Frijolón, y Rocha volvió a clamar:

- Que me pasés el condenado machete, hija; me va a apiar la cabeza este desgraciado.

Y mientras el otro seguía abalanzándosele con la cruceta, casi acorralándolo contra la máquina de moler, la pequeña alcanzó a correr bordeando el terraplén de leña, dirigiéndose luego hacia el rancho del maíz pujagua, donde encontró un enorme machete 28 , con un despalme nítido y reluciente, liviano y carnicero, y lo arrojó a su padre, bañada en llanto hasta la barbilla, y volvió a refugiarse detrás de la leña. Entre tanto, Rocha esquivó otro de los machetazos de Frijolón (que respiraba a bocanadas), y recogió la hoja metálica del suelo, dando un salto hacia atrás y poniéndose una vez más en guardia frente al otro, que revelaba ya el terror en su cara.

- Qué hacés allí parado, maricón, vení para probarte que a mí nadie me quita la mujer y se queda así como así- gruñó Frijolón, tambaleándose, ya no por la borrachera, sino por la metralla de machetazos fallidos que había descargado contra Rocha.

Rocha se mantuvo inmóvil, sombrío y absorto, percibiendo apenas el llanto de la niña, que se desgarraba la garganta a gritos, suplicando al otro que no le matara a su padre. Frijolón recordó su monta en el Venado, el pretal reventándole los nudillos, la cara burlona de Rocha y la indignación que se le arracimó en el cerebro, y descargó el machetazo más potente que pudo.

Rocha lo vio venir, cabeza fría, y esquivó el golpe, dejándolo perderse en su propia inercia. La cruceta siguió su rumbo, y se atascó en un tronco de guanábano seco a la izquierda de Rocha, y Frijolón comprendió que se había topado con la muerte. Con grave frialdad, Rocha alzó el brazo y dejó caer un machetazo furibundo sobre la cervical desprotegida de Frijolón, arrancándole un grito lúgubre que partió en dos la quietud de los potreros, mientras el cuerpo ya vencido se derrumbaba sobre la tierra hirviente. Rocha lo miró desplomarse, en la misma pose en que quedó luego de propinarle la herida mortal, y se horrorizó de verlo reincorporarse, a la deriva, dando pasos agigantados y torpes, en dirección totalmente opuesta a la suya, desde donde lo esperaba para terminar de matarlo. Entonces tuvo la horrible impresión de que la diferencia entre ver a un cerdo salir corriendo con la herida en la garganta y mirar a un hombre correr con la muerte metiéndosele por el cuello es que los cerdos no provocaban ese deseo inexplicable de matarse que le estaba provocando ahora Frijolón; que trataba inútilmente de resistir a la muerte, como si algo o alguien pudiera exonerarlo de la fatalidad que tan mortal herida representaba. Frijolón se fue quedando quieto, hasta que se desplomó poco a poco sobre sus rodillas, y cayó boca abajo sobre el zacate ya húmedo por la sangre.

Hacía poco menos de un día que había sobrevivido a los saltos infernales del Venado; menos de un día desde que pudo ensalzar su hombría y su fama en la plaza; menos de un día desde que se había propuesto cobrar la venganza que desde hacía mucho tenía cruzada en el pecho. Ahora, a pocas horas de la otra monta (pues, era sábado y la monta de fin de semana continuaba), debería estar huyendo hacia Cárdenas o Rivas, o pensando en raparse la cabeza para no ser reconocido, y perderse entre algún lugar recóndito de Nicaragua (quizás en La Isla, donde tenía viejos conocidos y parientes lejanos), a esperar que las aguas estuvieran tranquilas en Santa Cecilia y que su caso pasara a ser uno de esos casos olvidados por la policía y por la memoria volátil de la gente que, absorbida por la cotidianidad de la muerte, elegía olvidar este tipo de sucesos en el círculo de violencia en que nacían, crecían, se hacían hombres y morían los montadores de Santa Cecilia.

Pero Frijolón yace inmóvil, sobre la tierra donde las mujeres paren montadores...; inmóvil, sobre el desdén que hasta la muerte le habría de profesar a la Agustina (“¿dónde estará la Agustina, sobre qué montaña buscará hallar la muerte, en qué río estará buscando morir ahogada?... Qué me importa la Agustina...", piensa); inmóvil, sobre aquella realidad que ahora le está llegando de golpe y sin tregua. La muerte se le está trepando por la herida, y con ella, en 
ese último suspiro que lo separa del terreno de los muertos, le trepa al cerebro la horrible verdad de que la Martina nunca había sido suya, que
Cástulo Rocha nunca se la había quitado, y que toda su tragedia había sido una jugada macabra provocada por el guaro de la hombría.

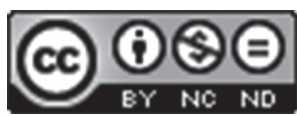

Este obra está bajo una licencia de Creative Commons Reconocimiento-NoComercial-SinObraDerivada 4.0 Internacional. 
